\title{
PARP inhibition improves the effectiveness of neural stem cell transplantation in experimental brain trauma
}

\author{
ZSOMBOR LACZA ${ }^{1,2}$, ESZTER M. HORVÁTH ${ }^{1,2}$, KATALIN KOMJÁTI ${ }^{2,3}$, TIBOR HORTOBÁGYI ${ }^{4}$, \\ CSABA SZABÓ ${ }^{2,3}$ and DAVID W. BUSIJA ${ }^{1}$ \\ ${ }^{1}$ Department of Physiology/Pharmacology, Wake Forest University School of Medicine, Winston-Salem, NC, USA; \\ ${ }^{2}$ Institute of Human Physiology and Clinical Experimental Research, Semmelweis University, Budapest, Hungary; \\ ${ }^{3}$ Inotek Pharmaceuticals Corporation, Beverly, MA, USA; ${ }^{4}$ Department of Pathology, University of Szeged, Szeged, Hungary
}

Received January 24, 2003; Accepted March 10, 2003

\begin{abstract}
Neural stem cell transplantation is a promising new treatment of ischemic or traumatic brain injury. We have now investigated the involvement of the peroxynitrite - poly(ADPribose) polymerase ( $\mathrm{ONOO}^{-}$- PARP) activation cascade in brain trauma and neural stem cell transplantation. The forelimb motor cortex of adult male rats was exposed to cold lesion $\left(-60^{\circ} \mathrm{C}\right)$ and motor function was monitored. Neural stem cells isolated from E14 rat embryos were labeled with brome deoxyuridine (BrDU) and injected into the injured cortex 6 days after the lesion. After another 6 days, the survival and differentiation of the grafted cells were investigated with immunohistochemistry. Increased production of $\mathrm{ONOO}^{-}$revealed by tyrosine nitration was seen in the lesion 2 days after transplantation. Animals treated with the $\mathrm{ONOO}^{-}$decomposition catalyst FP15 or the PARP inhibitor PJ34 had a significantly improved motor score, when compared to vehicle-treated controls. The neurological score further improved following stem cell grafting in the PJ34 treated, but not in the control animals. Six days after transplantation, differentiated BrDU positive cells were found in the cortical penumbra. The majority of these differentiated cells expressed an astrocyte marker and some of the cells expressed oligodendrocyte or neuronal markers. The number of surviving transplanted cells was significantly higher in the PJ34 treated group. Inhibition of the ONOO- - PARP activation cascade significantly
\end{abstract}

Correspondence to: Dr Zsombor Lacza, Wake Forest University School of Medicine, Medical Center Blvd., Winston-Salem, NC 27157, USA

E-mail: zlacza@mac.com

Abbreviations: BrDU, brome deoxy-uridine; DMEM, Dulbecco's modified Eagle medium; GFAP, glial fibrillary acidic protein; MBP, myelin basic protein; NO, nitric oxide; $\mathrm{ONOO}^{-}$, peroxynitrite; PARP, poly(ADP-ribose) polymerase; TTC, 2,3,5 triphenyl tetrazolium chloride

Key words: brain trauma, BrDU, cold lesion, neural stem cell transplantation, peroxynitrite, poly(ADP-ribose) polymerase (PARP) improves the effectiveness of neural stem cell transplantation and promotes rapid functional recovery.

\section{Introduction}

Stem cell transplantation is an emerging approach for the treatment of various diseases of the central nervous system. Naturally occurring stem cells can be found in the subventricular and hippocampal subgranular zones (1) and these cells respond to brain damage by proliferation and migration to the area of the injury $(2,3)$. The number of these endogenous stem cells is very limited. Therefore, grafting of exogenous stem cells may accelerate the natural regeneration process. Recent findings indicated that neural stem cell transplantation can be a viable approach for the treatment of brain trauma (4-6) or stroke (7-10). However, it is still not completely understood how these cells, endogenous or exogenous, are involved in the brain repair process (11).

Human trials with various neural stem cell transplantation strategies ended with both promising results and serious concerns (12-14). One major limitation of current approaches is the low number of surviving grafted cells $(12,15)$. Thus, in most cases the survival rate of the cells is below $10 \%$ and this situation places severe constraints on ultimate beneficial results. Marginal improvements in cell survival can be achieved by limiting apoptosis $(16,17)$, free radical production $(18)$, or lipid peroxidation $(19,20)$. Another approach for increasing the survival of grafted cells is the application of exogenous growth factors like GDNF $(21,22)$ or bFGF $(23-25)$. None of these methods can ensure the complete survival of the graft.

The constitutive nitric oxide (NO) production in the brain is responsible for the maintenance of cerebral blood flow (26) and for vasodilatory responses during various physiological situations. Additionally, NO has been shown to be an important protective factor during ischemia because of the effects on blood flow (27). However, excessive neuronal NO production during ischemia has been shown to be harmful for the tissues (28). In contrast to its direct vasodilator effect, the damaging properties of NO are mainly mediated by peroxynitrite $\left(\mathrm{ONOO}^{-}\right)$, its reaction product with superoxide. This reactive oxidant damages DNA by inducing single strand breaks, which activates the repair enzyme poly(ADP-ribose) polymerase 
Table I. Rat forelimb motor score. ${ }^{\mathrm{a}}$

\begin{tabular}{llll}
\hline Held by the tail & \multicolumn{1}{c}{1} & \multicolumn{1}{c}{2} & 3 \\
\hline Symmetry of movements & Twists (L) & Fails to twist (R) & Symmetrical movements \\
Forelimb flexion angle & $\approx 90^{\circ}$ & $>90^{\circ}$ & Complete extension \\
Walking & L moves slightly & L outstretches $<\mathrm{R}$ & Symmetrical response \\
Climbing the cage & Fails to climb & Left side weak & Normal
\end{tabular}

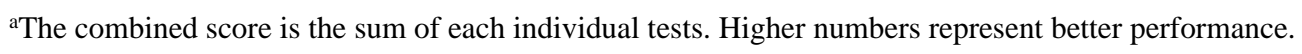

(PARP). The over-activation of PARP rapidly utilizes the available cellular NAD ${ }^{+}$and ATP stores. This results in a fast depletion of cellular energy pools, which ultimately leads to necrotic cell death (29). Inhibition of this cascade by an $\mathrm{ONOO}^{-}$decomposition catalyst or a PARP inhibitor has been shown to be an effective therapy in stroke $(30,31)$ and brain trauma $(32,33)$. Pharmacological inhibition of PARP activation may also be a viable approach for improving the outcome of stem cell transplantation by two ways. First, it may make the host tissue environment more receptive for a graft; and second, it may directly protect the transplanted cells from $\mathrm{ONOO}^{-}$induced necrosis.

The aim of the present study was to investigate the involvement of the PARP cascade in experimental brain trauma and neural stem cell transplantation. First, neurological function and lesion volume were measured in rats after cold lesion of the forelimb motor cortex treated with an $\mathrm{ONOO}^{-}$decomposition catalyst or a PARP inhibitor. Second, embryonic neural stem cell transplantation was applied after cold lesion. Tyrosine nitration, a footprint of peroxynitrite was measured. In addition, the effectiveness of the treatments on graft survival and neurological improvement was tested. Finally, we investigated the fate of the transplanted cells using immunohistochemistry and fluorescent confocal microscopy.

\section{Materials and methods}

All procedures were approved by the Animal Care and Use Committee of Wake Forest University School of Medicine. Surgical procedures were performed in aseptic conditions and the animals were regularly monitored for signs of inflammation or distress.

Brain trauma model. The cold lesion protocol was chosen to induce experimental brain trauma $(34,35)$. Adult male Wistar rats were anesthetized with halothane and the head was fixed in a stereotaxic frame with atraumatic earplugs. The scalp was incised and a circular craniectomy was made over the left motor cortex; special care was taken to keep the dura intact. A nickel coated brass stamp with a footprint of $3 \mathrm{~mm}$ in diameter was precooled to $-60^{\circ} \mathrm{C}$ with a mixture of dry ice and acetone and was lowered by a micromanipulator to touch the exposed dura for $3 \mathrm{~min}$. Following the lesion the wound was closed by surgical suture and the animal regained consciousness.

Lesion volume was evaluated 6 days after surgery. The animals were overanesthetized by sodium thiopenthal $(100 \mathrm{mg} /$ kg i.p.) and decapitated. The brain was removed and sliced to $1 \mathrm{~mm}$ thick sections and immersed in 1\% 2,3,5 triphenyl tetrazolium chloride (TTC) solution for $20 \mathrm{~min}$ followed by formalin fixation. The slices were scanned and the lesion volume was determined using Adobe Photoshop software.

Donor cell preparation. Timed pregnant E13 Wistar rats were given a single i.p. injection of $50 \mathrm{mg} / \mathrm{kg}$ brome deoxy uridine (BrDU) to label the dividing cells. The animal was anesthetized with sodium thiopenthal $24 \mathrm{~h}$ later and the embryos were excised and put in ice-cold Dulbecco's modified Eagle medium (DMEM). One embryo was fixed with formalin to check the effectiveness of BrDU labeling and the others were processed for the donor cell preparation. The embryos' brain cortices were isolated under a stereotaxic microscope and digested with $0.1 \%$ trypsin and $0.04 \%$ DNAse for $1 \mathrm{~h}$ at $37^{\circ} \mathrm{C}$. The sample was triturated with hypodermic needles in DMEM containing $0.04 \%$ DNAse to get a suspension of single cells and small clumps. Cell viability was measured with the trypan-blue exclusion method. The total cell number was also calculated in each case using a cell counting chamber. The cell suspension was kept on ice until grafting $(<4 \mathrm{~h})$.

Transplantation procedure. The animals received freshly isolated neural stem cell grafts 6 days after the cold lesion. We waited six days because it has been shown previously that edema formation is not present at this time (36). The dura mater was exposed under halothane anesthesia and 3 deposits of $3 \mu \mathrm{l}$ cell suspension were injected into the penumbra of the lesion with a Hamilton syringe equipped with a side-hole needle. Each cell graft was given $1 \mathrm{~mm}$ deep into the brain and contained approximately 50,000 cells $/ \mu 1$. The wound was closed and the animals were returned to their cages.

Neurological scoring. The animals suffered an isolated cortical lesion of the right forelimb motor cortex and were tested 1 day after cold lesion, 6 days later just before transplantation, and 1 and 6 days after transplantation. No other motor deficit was detectable and the animals had a normal behavior. Neurological scoring was performed using the rat stroke motor score (37) with modifications to specifically measure forelimb function (Table I). Both evoked and spontaneous movements were tested and the scoring was performed by the same observer in a blinded fashion.

Treatment groups. Animals were randomly assigned to three treatment groups: untreated control or treated with the $\mathrm{ONOO}^{-}$ 
decomposition catalyst FP15 (10 mg/kg/day, i.p.) $(33,38)$ or the PARP inhibitor PJ34 (10 mg/kg/day, i.p.) $(30,39)$. The first dose was given immediately following cold lesion and was administered once daily afterwards. To test the effect of the treatments on lesion volume the protocol was discontinued on the 6th day after lesion, at the intended time of grafting. The brains were removed and stained with TTC to evaluate lesion volume. To test the effect of the treatments on graft survival the animals received transplants 6 days after cold lesion and were sacrificed a further 6 days later. The brains were removed, fixed in $10 \%$ buffered formalin, and paraffin-embedded sections were prepared.

Immunohistochemistry. For evaluation of graft survival and differentiation $5 \mu \mathrm{m}$ thick sections were prepared and every 50th section was mounted on slides.

The sections were deparaffinized and the BrDU antigen was exposed using the Retrievagen kit (BD Pharmingen, San Diego, CA). The sections were incubated with a 1:10 dilution of biotinylated anti-BrDU antibody (BD Pharmingen) for $3 \mathrm{~h}$ at $20^{\circ} \mathrm{C}(40)$. Secondary labeling was achieved by Alexa Fluor 488 conjugated streptavidin (Molecular Probes, Eugene, OR).

Cell line specific markers were used to identify differentiated cells. Anti-glial fibrillary acidic protein (GFAP) mouse monoclonal antibody (Chemicon, Temecula, CA) was used to stain astrocytes $\left(1 \mu \mathrm{g} / \mathrm{ml}, 1 \mathrm{~h}, 20^{\circ} \mathrm{C}\right)$, secondary labeling was achieved by a red-fluorescent Zenon kit (Molecular Probes). Anti-myelin basic protein (MBP) mouse monoclonal antibody (Chemicon) was used to identify oligodendrocytes $\left(1: 100\right.$ dilution, $\left.1 \mathrm{~h}, 20^{\circ} \mathrm{C}\right)$. Anti-neurofilament 68 rabbit polyclonal antibody (Chemicon) was used to identify neurons $\left(1: 100\right.$ dilution, overnight, $\left.4^{\circ} \mathrm{C}\right)$. Alexa-Fluor 546 conjugated goat IgG (Molecular Probes) was used as the secondary antibody. Staining with the anti-BrDU antibody always followed the lineage specific labeling (see above).

The sections were visualized by confocal scanning fluorescent microscopy (Zeiss Axiovert 100M). Threedimensional visualization of the cells was achieved by stepwise scanning of $1 \mu \mathrm{m}$ thick optical sections and software reconstitution. This procedure allowed us to determine whether the 2 labels belonged to a single cell.

For quantitation purposes nine sections from each brain were evaluated covering the center of the lesion. The BrDU labeling in these sections was visualized by horseradish peroxidase conjugated streptavidin followed by reaction with diaminobenzidine. Nuclei were counterstained with hematoxylin. The sections were observed using bright field microscopy. The number and distribution of BrDU positive cells were calculated by an observer blinded to the treatment group of the animals.

Immunohistochemical detection of tyrosine nitration was performed 2 and 6 days after grafting. The deparaffinized sections were treated with $0.3 \%$ hydrogen peroxide for $15 \mathrm{~min}$ to block endogenous peroxidase activity and then rinsed briefly in $10 \mathrm{mM} \mathrm{pH} 7.4$ phosphate buffered saline (PBS). Nonspecific binding was blocked by incubating the slides for $1 \mathrm{~h}$ in PBS containing 2\% goat serum. Mouse monoclonal antinitrotyrosine antibody (Upstate Biotechnology, Lake Placid, NY) and isotype-matched control antibody was applied in a dilution of 1:200 for $1 \mathrm{~h}$ at room temperature. After extensive washing ( $3 \times 10 \mathrm{~min}$ ) with $0.25 \%$ Triton/PBS, immunoreactivity was detected with a biotinylated horse anti-mouse secondary antibody and the avidin-biotin-peroxidase complex (ABC) both supplied in the Vector Elite kit (Vector Laboratories, Burlingame, CA). Color was developed using Ni-DAB substrate-kit (Vector Laboratories, Burlingame, CA). Sections were then counterstained with nuclear fast red, dehydrated and mounted in Permount.

All drugs and chemicals were obtained from Sigma Chemicals (St. Louis, MO), unless stated otherwise.

Statistics and data analysis. Data are presented as means \pm $\mathrm{SEM}, \mathrm{n}$ represents the number of animals used. Statistics were carried out using ANOVA or ANOVA for repeated measures followed by Fisher's protected Least Significant Different test for post-hoc comparisons. A p-value $<0.05$ was considered significant.

\section{Results}

Cold lesion. The pre-cooled stamp caused a wedge-like penetrating lesion which affected all layers of the cortex with an average volume of $10.5 \pm 1.5 \mathrm{~mm}^{3}$. The lesion affected the left forelimb motor cortex and resulted in a highly reproducible, isolated motor deficit in the right forelimb (neurological score, $8.3 \pm 0.5$ on a scale of 4 to 12 ).

Treatment of the animals with either the ONOOdecomposition catalyst FP15 or the PARP inhibitor PJ34 failed to decrease the volume of the lesion (Fig. 1). However, both treatment groups had a significantly higher neurological score than the controls (control, 7.5 $\pm 0.2 ; \mathrm{PJ} 34,8.1 \pm 0.3, \mathrm{p}<0.01$; FP15, 8.8 $\pm 0.8, \mathrm{p}<0.01)$ (Fig. 1).

Cold lesion followed by transplantation. Staining of the tissues with the anti-nitrotyrosine antibody revealed that there is intense $\mathrm{ONOO}^{-}$production in the lesioned brain during the first days following transplantation (Fig. 2). ONOO- production was most pronounced after 2 days and it was markedly reduced on the 6th day. This finding indicated that the $\mathrm{ONOO}^{-}$- PARP cascade induced damage occurs during the first few days after grafting. No positive staining could be seen in the isolated embryos proving that the ONOO- induced damage occurred after grafting, not in the embryos (not shown).

Histological evaluation of the transplanted brains was carried out 6 days after grafting. BrDU positive transplanted cells were found in each brain section, which contained the lesion and no cells were found anywhere outside the affected area or in the other hemisphere. The labeled cells were similar in appearance to the surrounding host tissue.

Quantitative evaluation of the surviving graft was carried out by counting the BrDU positive cells in the brain sections. The number of surviving grafted cells was significantly higher in the PJ34-treated group 6 days after transplantation (Fig. 3). The neurological score of the PJ34-treated animals was significantly improved compared to the untreated control group. Interestingly, this improvement started as early as 1 day after transplantation and was still pronounced after 6 days (Fig. 3). 
A

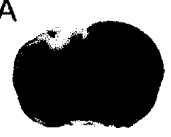

control
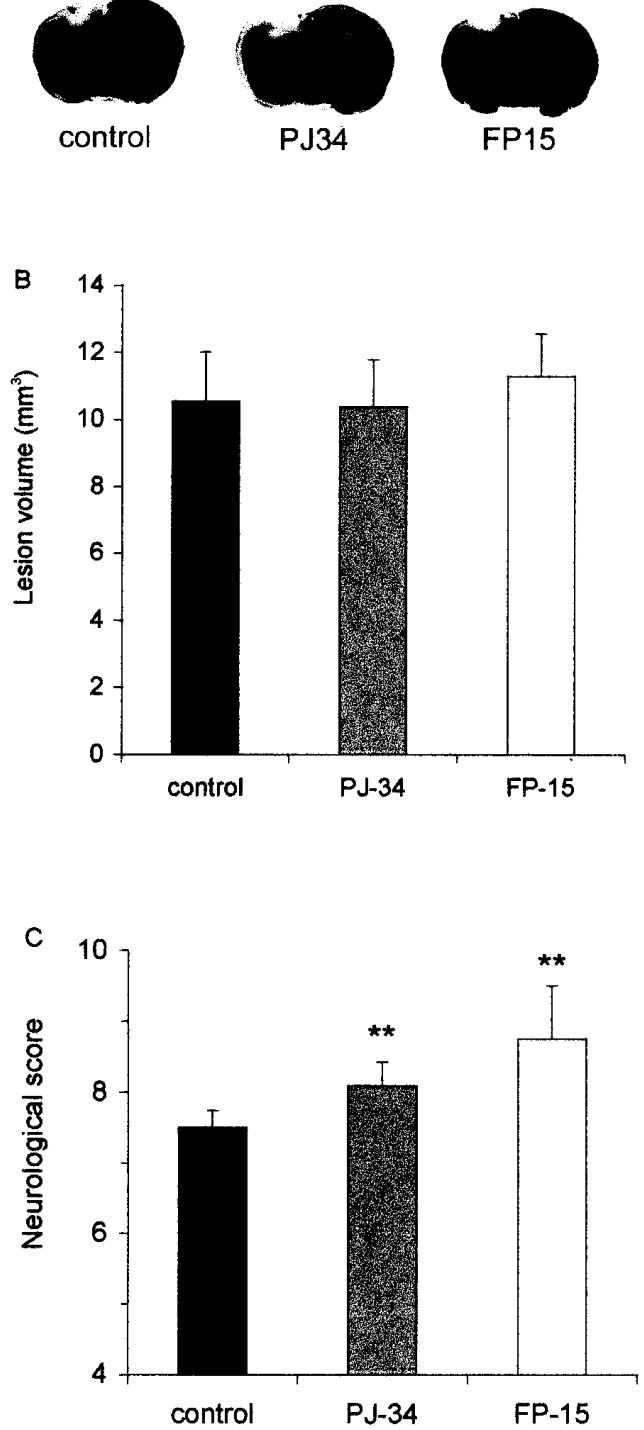

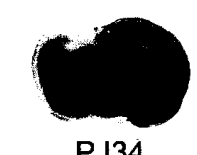

Figure 1. The effect of the inhibition of the ONOO- - PARP activation cascade in cold lesion. A, shows respective brain slices stained with TTC 6 days after the lesion. B, shows the volume of the lesion. There was no significant difference in lesion volume among the three treatment groups. C, shows the neurological score of the animals 6 days after the lesion. Both the PARP inhibitor PJ34 $(n=12)$ and the $\mathrm{ONOO}^{-}$decomposition catalyst FP15 $(n=4)$ improved the neurological score compared to the control group $(n=11)$. Values are expressed as mean \pm SEM. The asterisks represent $\mathrm{p}<0.01$ versus control.

The fate of the grafted cells. Immunohistochemical labeling showed that some BrDU positive cells had the morphology of astrocytes and expressed GFAP (Fig. 4). These cells were mainly located in the penumbra and were similar in appearance to the surrounding unlabeled astrocytes. Similarly, some BrDU positive grafted cells expressed MBP, an oligodendrocyte marker or neurofilament 68 , a neuronal marker. However, these other cell types were much fewer than the astrocytic cells, typically 0 or 1 in a section (not shown). All the surviving BrDU positive cells, which were found deeper in the lesion had an undifferentiated phenotype and did not express lineage specific markers. Three-dimensional reconstitution of the triple-labeled cells confirmed that the BrDU positive nucleus was enclosed by the lineage-specific labeled cytoplasm.

\section{Discussion}

The present study demonstrated the beneficial effect of PARP inhibition on brain trauma and neural stem cell transplantation. Treatment with a PARP inhibitor improved the neurological score after the lesion, and increased it even further following stem cell transplantation. High $\mathrm{ONOO}^{-}$production coincides with the loss of the majority of the grafted cells, and inhibition of the PARP activation cascade significantly increases the number of surviving cells.

The present study found elevated $\mathrm{ONOO}^{-}$production during the first few days after transplantation, and treatment with a PARP inhibitor significantly improved the survival of the graft. Other studies using various transplantation methods agree that a dramatic loss of the transplanted cells occurs during the first week of grafting (15). Improvement in graft survival found in the present study may be the result of two complimentary effects: the treatment may make the host more receptive to the graft, or the treatment can have a direct protective effect on the transplanted cells themselves. In the present study we found that the PARP-inhibitor treated animals exhibited better neurological scores than the controls on the day of grafting, which may indicate better reception on the host side. However, this treatment cannot achieve the full survival of the graft and it is possible that combination approaches, like free radical and oxidant scavenging plus necrosis and apoptosis blockade, may be more effective.

The majority of the surviving cells, which were located in the core of the lesion were still undifferentiated after 6 days. However, most of the cells which were found in the penumbra differentiated into astrocytes. During 6 days, these cells migrated from the place of injection, differentiated to astrocytes, and dispersed evenly in the brain surrounding the lesion core. This process indicates that there is a need for newly formed astrocytes in the penumbra and the differentiation of the multipotent cells is mainly restricted to the astrocytic lineage.

The differentiation of stem or precursor cells in the brain is largely dependent on growth factors (41). The local concentration of the growth factor mixture determines the fate of the multipotent cells, i.e. neuronal or glial differentiation. The present study found that most of the differentiated grafted cells had the phenotype of astrocytes. Recent studies indicated the active role of these cells in the neuronal repair process by the production of growth factors (42). It is possible, therefore, that the newly formed glial cells are important in the differentiation of the other, remaining stem cells.

A surprising finding in the present study is the significantly better functional recovery of the PARP-inhibitor treated animals compared to the untreated controls. This observation is consistent with previous studies using other brain trauma or stroke models $(30,32)$. Similar to a previous study in traumatic brain injury (32), the protective effect of PARP inhibition could not be attributed to salvaging significant amounts of lesioned tissue, and thus it may indicate that functional improvement in some cases is not closely correlated to the extent of brain damage. Transplantation of stem cells, which readily differentiate into penumbral astrocytes improves performance even further. These new astrocytes may help to maintain the neurological function in the affected, but 


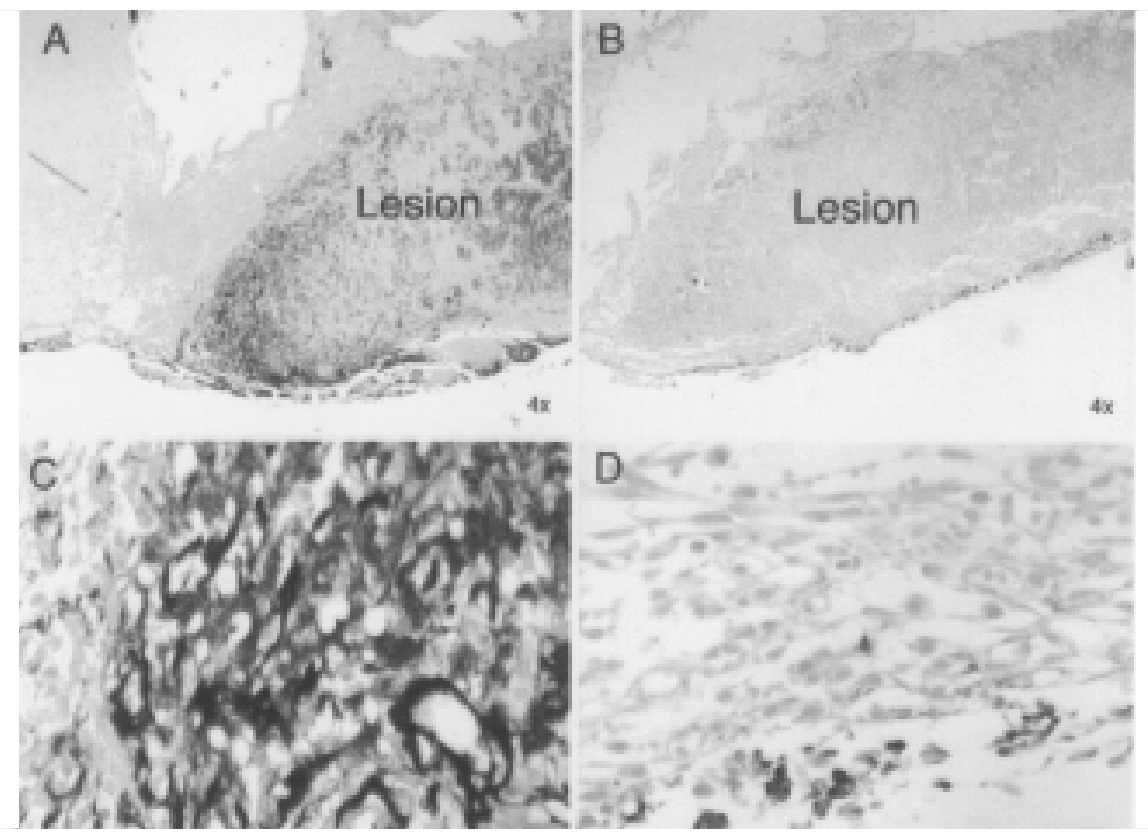

Figure 2. Nitrotyrosine formation during transplantation. A and C, show anti-nitrotyrosine immunohistochemistry performed 2 days after grafting. Note the intense staining in the lesion area, especially close to the brain surface or in the penumbra. B and D, show nitrotyrosine staining 6 days after grafting. The intensity of the staining is markedly reduced. Only the surface of the lesion shows significant tyrosine nitration.
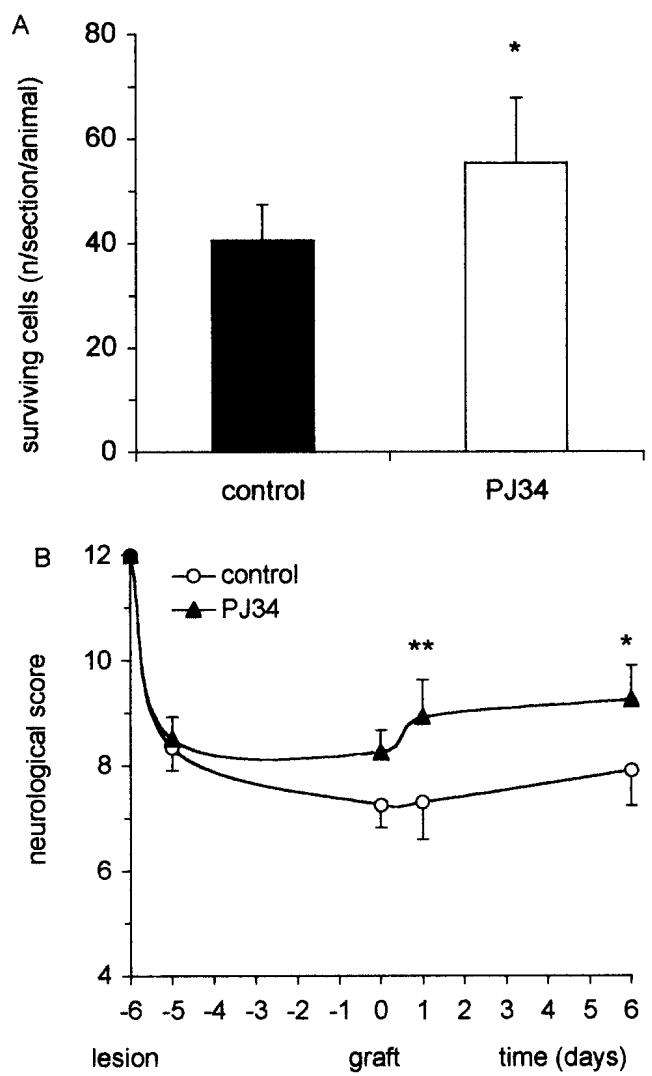

Figure 3. The effect of PARP inhibition on the grafted cells. A, shows the number of surviving transplanted cells 6 days after grafting. The animals treated with PJ34 $(n=6)$ had a significantly higher number of surviving cells than the untreated controls $(n=5)$. Nine sections were evaluated in each animal. B, shows the neurological score of the animals on a scale of 4-12, higher score represents better performance. One day after the cold lesion all animals had a significant neurological deficit and there was no difference between the treatment groups. Grafting was performed on day 0 following which the animals treated with PJ34 $(n=6)$ had a significantly better score than the controls $(\mathrm{n}=5) .{ }^{*} \mathrm{p}<0.05 .{ }^{* *} \mathrm{p}<0.01$

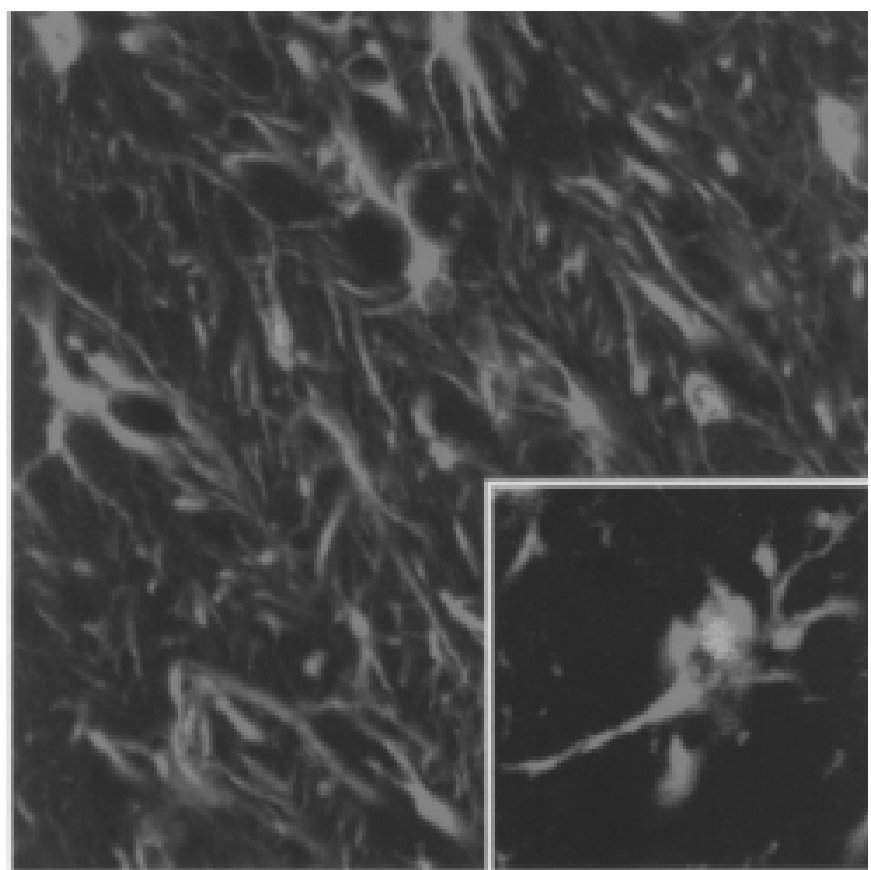

Figure 4. BrDU positive transplanted cells express the astrocyte-marker GFAP. Transplanted cell nuclei are labeled with BrDU (green), while the astrocyte-specific cytoplasmic marker GFAP is red. Four differentiated astrocytes are shown, which are similar to other astrocytes in the vicinity. Insert shows a BrDU positive astrocyte in high magnification.

salvageable tissue by promoting regeneration with increased growth factor production (43). This view is supported by a study of Philips $e t a l$, in which significant functional recovery was found after brain trauma, which was attributed to grafted neural growth factor (NGF) overproducing cells (5). 
We conclude that the ONOO- - PARP activation cascade plays a pathogenetic role in brain trauma and regeneration. Treatment with a PARP inhibitor may help to make the host brain more receptive for neural stem cell grafting and can promote rapid functional recovery. These results also suggest that stem cell grafts are more likely to serve a supportive function in the recovery process rather than simply 'filling the hole'. This view of neural stem cell grafting may promote the design of novel therapeutic approaches, where early neuroprotective therapy prepares the brain for the subsequent transplantation surgery. This approach may ultimately lead to an optimized grafting strategy, which utilizes a small number of stem cells and yet significantly improves functional recovery.

\section{Acknowledgements}

The authors are grateful to Ken Grant for his help with confocal microscopy. This study was supported by grants from the National Institute of Health to D.W.B. (HL-30260; HL-50557; HL-46558) and to C.S. (2R44NS37985-02A2) and the American Heart Association to D.W.B. (Mid Atlantic Affiliate grant 99512724 and Bugher Foundation award 0270114N). Z.L. and T.H. were partially supported by Hungarian National Eötvös Fellowships.

\section{References}

1. Gage FH: Mammalian neural stem cells. Science 287: 1433-1438, 2000.

2. Englund U, Fricker-Gates RA, Lundberg C, Bjorklund A and Wictorin K: Transplantation of human neural progenitor cells into the neonatal rat brain: extensive migration and differentiation with long-distance axonal projections. Exp Neurol 173: 1-21, 2002.

3. Iwai M, Sato K, Omori N, Nagano I, Manabe Y, Shoji M and Abe K: Three steps of neural stem cells development in gerbil dentate gyrus after transient ischemia. J Cereb Blood Flow Metab 22: 411-419, 2002

4. Kanelos SK and McDeavitt JT: Neural transplantation: potential role in traumatic brain injury. J Head Trauma Rehabil 13: 1-9, 1998.

5. Philips MF, Mattiasson G, Wieloch T, Bjorklund A, Johansson BB, Tomasevic G, Martinez-Serrano A, Lenzlinger PM, Sinson G, Grady MS and McIntosh TK: Neuroprotective and behavioral efficacy of nerve growth factortransfected hippocampal progenitor cell transplants after experimental traumatic brain injury. J Neurosurg 94: 765-774, 2001.

6. Sinson G, Voddi M and McIntosh TK: Combined fetal neural transplantation and nerve growth factor infusion: effects on neurological outcome following fluid-percussion brain injury in the rat. J Neurosurg 84: 655-662, 1996.

7. Chen J, Sanberg PR, Li Y, Wang L, Lu M, Willing AE, Sanchez-Ramos J and Chopp M: Intravenous administration of human umbilical cord blood reduces behavioral deficits after stroke in rats. Stroke 32: 2682-2688, 2001.

8. Veizovic T, Beech JS, Stroemer RP, Watson WP and Hodges H: Resolution of stroke deficits following contralateral grafts of conditionally immortal neuroepithelial stem cells. Stroke 32: 1012-1019, 2001.

9. Borlongan CV, Koutouzis TK, Jorden JR, Martinez R, Rodriguez AI, Poulos SG, Freeman TB, McKeown P, Cahill DW, Nishino H and Sanberg PR: Neural transplantation as an experimental treatment modality for cerebral ischemia. Neurosci Biobehav Rev 21: 79-90, 1997.

10. Saporta S, Borlongan CV and Sanberg PR: Neural transplantation of human neuroteratocarcinoma (hNT) neurons into ischemic rats. A quantitative dose-response analysis of cell survival and behavioral recovery. Neuroscience 91: 519-525, 1999.
11. Rossi F and Cattaneo E: Opinion: neural stem cell therapy for neurological diseases: dreams and reality. Nat Rev Neurosci 3: 401-409, 2002.

12. Brundin P, Dunnett S, Bjorklund A and Nikkhah G: Transplanted dopaminergic neurons: more or less? Nat Med 7: 512-513, 2001.

13. Freed CR, Greene PE, Breeze RE, Tsai WY, DuMouchel W, Kao R, Dillon S, Winfield H, Culver S, Trojanowski JQ, Eidelberg D and Fahn S: Transplantation of embryonic dopamine neurons for severe Parkinson's disease. N Engl J Med 344: 710-719, 2001.

14. Isacson O, Bjorklund L and Pernaute RS: Parkinson's disease: interpretations of transplantation study are erroneous. Nat Neurosci 4: 553, 2001.

15. Brundin P, Karlsson J, Emgard M, Schierle GS, Hansson O, Petersen A and Castilho RF: Improving the survival of grafted dopaminergic neurons: a review over current approaches. Cell Transplant 9: 179-195, 2000.

16. Mundt-Petersen U, Petersen A, Emgard M, Dunnett SB and Brundin P: Caspase inhibition increases embryonic striatal graft survival. Exp Neurol 164: 112-120, 2000.

17. Schierle GS, Hansson O, Leist M, Nicotera P, Widner $H$ and Brundin P: Caspase inhibition reduces apoptosis and increases survival of nigral transplants. Nat Med 5: 97-100, 1999.

18. Nakao N, Frodl EM, Widner H, Carlson E, Eggerding FA, Epstein CJ and Brundin P: Overexpressing $\mathrm{Cu} / \mathrm{Zn}$ superoxide dismutase enhances survival of transplanted neurons in a rat model of Parkinson's disease. Nat Med 1: 226-231, 1995.

19. Bjorklund L, Spenger C and Stromberg I: Tirilazad mesylate increases dopaminergic neuronal survival in the in Oculo grafting model. Exp Neurol 148: 324-333, 1997.

20. Brundin P, Pogarell O, Hagell P, Piccini P, Widner H, Schrag A, Kupsch A, Crabb L, Odin P, Gustavii B, Bjorklund A, Brooks DJ, Marsden CD, Oertel WH, Quinn NP, Rehncrona S and Lindvall O: Bilateral caudate and putamen grafts of embryonic mesencephalic tissue treated with lazaroids in Parkinson's disease. Brain 123: 1380-1390, 2000.

21. Sinclair SR, Svendsen CN, Torres EM, Martin D, Fawcett JW and Dunnett SB: GDNF enhances dopaminergic cell survival and fibre outgrowth in embryonic nigral grafts. Neuroreport 7: 2547-2552, 1996.

22. Rosenblad C, Kirik D, Devaux B, Moffat B, Phillips HS and Bjorklund A: Protection and regeneration of nigral dopaminergic neurons by neurturin or GDNF in a partial lesion model of Parkinson's disease after administration into the striatum or the lateral ventricle. Eur J Neurosci 11: 1554-1566, 1999.

23. Mayer E, Dunnett SB, Pellitteri R and Fawcett JW: Basic fibroblast growth factor promotes the survival of embryonic ventral mesencephalic dopaminergic neurons-I. Effects in vitro. Neuroscience 56: 379-388, 1993.

24. Mayer E, Fawcett JW and Dunnett SB: Basic fibroblast growth factor promotes the survival of embryonic ventral mesencephalic dopaminergic neurons-II. Effects on nigral transplants in vivo. Neuroscience 56: 389-398, 1993.

25. Takayama H, Ray J, Raymon HK, Baird A, Hogg J, Fisher LJ and Gage FH: Basic fibroblast growth factor increases dopaminergic graft survival and function in a rat model of Parkinson's disease. Nat Med 1: 53-58, 1995.

26. Kovach AG, Szabo C, Benyo Z, Csaki C, Greenberg JH and Reivich M: Effects of NG-nitro-L-arginine and L-arginine on regional cerebral blood flow in the cat. J Physiol 449: 183-196, 1992.

27. Huang Z, Huang PL, Ma J, Meng W, Ayata C, Fishman MC and Moskowitz MA: Enlarged infarcts in endothelial nitric oxide synthase knockout mice are attenuated by nitro-L-arginine. J Cereb Blood Flow Metab 16: 981-987, 1996.

28. Iadecola C: Bright and dark sides of nitric oxide in ischemic brain injury. Trends Neurosci 20: 132-139, 1997.

29. Liaudet L, Soriano FG and Szabo C: Biology of nitric oxide signaling. Crit Care Med 28: N37-N52, 2000.

30. Abdelkarim GE, Gertz K, Harms C, Katchanov J, Dirnagl U, Szabo C and Endres M: Protective effects of PJ34, a novel, potent inhibitor of poly(ADP-ribose) polymerase (PARP) in in vitro and in vivo models of stroke. Int J Mol Med 7: 255260, 2001.

31. Eliasson MJ, Sampei K, Mandir AS, Hurn PD, Traystman RJ, Bao J, Pieper A, Wang ZQ, Dawson TM, Snyder SH and Dawson VL: Poly(ADP-ribose) polymerase gene disruption renders mice resistant to cerebral ischemia. Nat Med 3: 1089-1095, 1997. 
32. Whalen MJ, Clark RS, Dixon CE, Robichaud P, Marion DW, Vagni V, Graham SH, Virag L, Hasko G, Stachlewitz R, Szabo C and Kochanek PM: Reduction of cognitive and motor deficits after traumatic brain injury in mice deficient in poly(ADP-ribose) polymerase. J Cereb Blood Flow Metab 19: 835-842, 1999.

33. Zhang X, Chen J, Graham SH, Du L, Kochanek PM, Draviam R, Guo F, Nathaniel PD, Szabó C, Watkins SC and Clark RSB: Intranuclear localization of apoptosis-inducing factor and large scale DNA fragmentation after traumatic brain injury in rats and in neuronal cultures exposed to peroxynitrite. J Neurochem 82: 181-191, 2002

34. Hortobagyi T, Hortobagyi S, Gorlach C, Harkany T, Benyo Z, Gorogh T, Nagel W and Wahl M: A novel brain trauma mode in the mouse: effects of dexamethasone treatment. Pflugers Arch 441: 409-415, 2000.

35. Gorlach C, Hortobagyi T, Benyo Z and Wahl M: Aminoguanidine reduces brain lesion volume after cold injury in the rat. Pflugers Arch 440: 309-314, 2000

36. Schneider GH, Hennig S, Lanksch WR and Unterberg A: Dynamics of posttraumatic brain swelling following a cryogenic injury in rats. Acta Neurochir 60 (Suppl.): 437-439, 1994.

37. Garcia JH, Wagner S, Liu KF and Hu XJ: Neurological deficit and extent of neuronal necrosis attributable to middle cerebral artery occlusion in rats. Statistical validation. Stroke 26: 627634, 1995.
38. Szabó C, Mabley JG, Moeller SM, Shimanovich R, Pacher P, Virág L, Soriano FG, VanDuzer JH, Williams W, Salzman AL and Groves JT: Pathogenetic role of peroxynitrite in the development of diabetes and diabetic vascular complications: studies with FP15, a novel potent peroxynitrite decomposition catalyst. Mol Med 8: 571-580, 2002.

39. Jagtap P, Soriano FG, Virag L, Liaudet L, Mabley J, Szabo E, Hasko G, Marton A, Lorigados CB, Gallyas FJ, Sumegi B, Hoyt DG, Baloglu E, VanDuzer J, Salzman AL, Southan GJ and Szabo C: Novel phenanthridinone inhibitors of poly (adenosine 5'-diphosphate-ribose) synthetase: potent cytoprotective and antishock agents. Crit Care Med 30: 1071-1082, 2002.

40. Mokry J and Nemecek S: Immunohistochemical detection of cells labeled with bromodeoxyuridine after neural transplantation. Mol Chem Neuropathol 25: 235-245, 1995.

41. Bartlett PF, Brooker GJ, Faux CH, Dutton R, Murphy M, Turnley A and Kilpatrick TJ: Regulation of neural stem cell differentiation in the forebrain. Immunol Cell Biol 76: 414-418, 1998.

42. Song H, Stevens CF and Gage FH: Astroglia induce neurogenesis from adult neural stem cells. Nature 417: 39-44, 2002.

43. Hortobagyi T, Harkany T, Reisch R, Urbanics R, Kalman M, Nyakas C and Nagy Z: Neurotrophin-mediated neuroprotection by solid fetal telencephalic graft in middle cerebral artery occlusion: a preventive approach. Brain Res Bull 47: 185-191, 1998. 